\title{
Virus status of western flower thrips (Frankliniella occidentalis) does not affect their response to a thrips lure or host plant volatiles in a Y-tube olfactometer
}

\author{
M.M. Davidson, S.M. Skill, R.C. Butler, M-C. Nielsen, S. Keenan and S.R. Bulman \\ The New Zealand Institute for Plant E Food Research Limited, Private Bag 4704, \\ Christchurch, New Zealand \\ Corresponding author: Melanie.davidson@plantandfood.co.nz
}

\begin{abstract}
The impact of tospovirus infection on the behaviour of western flower thrips (Frankliniella occidentalis) was evaluated in a Y-tube olfactometer. The response of female western flower thrips, with or without a tospovirus (Tomato spotted wilt virus, TSWV) to a thrips lure (methyl isonicotinate, MI), and chrysanthemum buds was recorded. Compared to the blank arm, significantly more thrips chose the odour-laden arm of the Y-tube when it contained MI $(65 \%, \mathrm{P}<0.01)$. However, chrysanthemum buds did not significantly $(\mathrm{P}>0.16)$ increase the percentage of thrips that chose the odour-laden arm over and above the clean-air arm, but thrips (virus-free and infected) moved more quickly to the end of either arm when a bud was present. The virus status of thrips was confirmed with RT-PCR. The presence of the virus in the vector did not substantially affect the behavioural response of the vector to a lure or host-plant material $(\mathrm{P}>0.4)$.
\end{abstract}

Keywords Frankliniella occidentalis, vector, tospovirus, methyl isonicotinate, semiochemical, host plant.

\section{INTRODUCTION}

Western flower thrips (Frankliniella occidentalis Pergande) is one of the major thrips pest species in the world (Whitfield et al. 2005), although in New Zealand it is largely restricted to covered crops (Martin et al. 2005). It can cause direct damage, as well as vectoring a number of tospoviruses (Jones 2005) to a wide range of ornamental, horticultural, and vegetable crops. In addition to Tomato spotted wilt virus (TSWV) and Impatiens necrotic spot virus that are recorded in New Zealand, F. occidentalis is known to vector three other tospoviruses. The ability to differentially attract virus-infected thrips could improve surveillance of new viruses for biosecurity, and monitoring in crops for pest and disease management.

Viruses have been shown to alter an insect vector's locomotor behaviour, feeding behaviour, development and longevity (Maris et al. 2004; Inoue \& Sakurai 2006; Lima-Camara et al. 2011; Stafford et al. 2011). Aedes aegypti infected with the dengue fever virus were more active than uninfected mosquitoes (Lima-Camara et al. 2011). Thrips tabaci adult lives were shortened when they were infected with TSWV (Inoue \& Sakurai 2006). TSWV-infected male western flower thrips were found to feed longer and probed more than 
uninfected males (Stafford et al. 2011). Western flower thrips larvae on TSWV-infected plants were found to develop more rapidly than those on uninfected plants (Maris et al. 2004). Maris et al. (2004) also found more female western flower thrips on TSWV-infected pepper plants (Capsicum annuum) than uninfected plants. These influences on thrips behaviour could affect the dispersal and population growth of the infected thrips that in turn may affect the spread of the virus. Greater knowledge of these factors may improve our ability to detect and monitor such insectvectored viruses.

The present study examined whether the presence of a tospovirus in F. occidentalis affected their behaviour toward a thrips lure, methyl isonicotinate (MI) or host plant volatiles. The thrips lure, MI, has been shown to increase trap capture of a range of thrips species, including western flower thrips (Davidson et al. 2007; Teulon et al. 2007; Teulon et al. 2011) and is therefore a potential tool for monitoring thrips vectors of tospoviruses. Additionally, the response of virus-free or infected thrips to a known host plant, chrysanthemum buds, Dendranthema grandiflora (cv. Onyx time yellow) was examined to determine if their response differed.

\section{MATERIALS AND METHODS}

\section{Insects and plant material}

Virus-infected F. occidentalis were from a colony maintained on flowering chrysanthemums, Dendranthema grandiflora (cv. Onyx time yellow), that had been established in 2001 from wild thrips collected from commercial greenhouses (Auckland, New Zealand). Plants and thrips were contained in three Perspex cages (five plants per cage) at $25 \pm 2^{\circ} \mathrm{C}$ under a $14: 10 \mathrm{~h}$ light:dark cycle.

Only first instar thrips larvae acquire the tospovirus, which can then be transmitted throughout their life (Wetering et al. 1996). Thus, virus-free western flower thrips were obtained using a method modified from Murai \& Ishii (1982) and Teulon (1992). Females were collected from the colony and held in $30 \mathrm{ml}(27 \mathrm{~mm}$ diameter, $40 \mathrm{~mm}$ tall) polyethylene vials (Biolab Limited, Auckland, New Zealand), with both ends removed. Females laid eggs into $0.05 \mathrm{ml}$ $10 \%$ sucrose solution held between two layers of Parafilm ${ }^{\circledR}$ covering one end of the vial, while the other end was covered with a single layer of Parafilm ${ }^{\circledR}$. Vials were incubated at $25^{\circ} \mathrm{C}(60 \%$ $\mathrm{RH}, 16: 8 \mathrm{~h}$ light:dark cycle) for a $24 \mathrm{~h}$ period in a controlled environment cabinet (Contherm Scientific Limited, Lower Hutt, New Zealand). Females were then removed from the vials, and the vials were placed inside a clear plastic box $(650 \mathrm{ml}$, Tellfresh, Australia) that was then held in the controlled environment cabinet. Eggs were observed every $24 \pm 2 \mathrm{~h}$. Once they had reached the red-eye stage, the top layer of Parafilm ${ }^{\circledR}$ was removed and the excess sucrose solution absorbed with filter paper (Whatman 1). They were placed on virus-free bean pods (Phaseolus vulgaris) in a glass jar (500 ml) lined with moistened filter paper, covered with thrips-proof mesh. Bean pods with newly emerged first-instar larvae were transferred onto virus-free bean plants. The process was repeated every week for 5 weeks to ensure that a colony established. The bean plants used for the colony were grown in a controlled environment cabinet (Convion E15, Controlled Environment Limited, Canada) (30-40 plants at various ages) with a temperature maintained at $24 \pm 1^{\circ} \mathrm{C}$, RH 70\% and a 16:8 h light:dark cycle. A tobacco plant (Nicotiana tabacum) was placed in the cabinet to monitor for the presence of TSWV in the virus-free thrips colony.

Chrysanthemum buds recently infested with thrips, but with all thrips removed prior to the Y-tube experiment, were obtained from laboratory colony cages. A single bud from a plant of the appropriate type was excised approximately $2 \mathrm{~cm}$ below the pedicel. The stem of the bud was wrapped in moistened cotton wool wrapped in Parafilm ${ }^{\circledR}$ and placed within a $4 \mathrm{ml}$ vial attached to the Wheaton apparatus and Y-tube olfactometer.

\section{Y-tube olfactometer experiments}

The response of virus-free or virus-infected female F. occidentalis, starved overnight, toward a volatile compound or flower buds was evaluated in a glass Y-tube olfactometer following the method described by Koschier et al. (2000) and 
Davidson et al. (2006). The Y-tube $\left(45^{\circ}\right.$ between branching arms of $60 \mathrm{~cm}$ long, $5 \mathrm{~mm}$ internal diameter), was positioned at an inclining angle of $25^{\circ}$ and illuminated from above by a halogen lamp (780 lux, Beha digital Lux Hi Tester 93-1065L, Germany) located in a darkened, air-conditioned room $\left(25 \pm 1^{\circ} \mathrm{C}\right)$.

Methyl isonicotinate $(1 \mu \mathrm{l})$ (Sigma Aldrich, Germany), was applied to filter paper in one $4 \mathrm{ml}$ vial and $1 \mu \mathrm{l}$ of hexane was applied to filter paper in the second vial (blank control). Air was drawn through activated charcoal before entering the Wheaton apparatus and Y-tube using a suction pump (AR Harris Co. Ltd, New Zealand). Airflow was $5 \mathrm{~cm} / \mathrm{s}$ through each arm and $10 \mathrm{~cm} / \mathrm{s}$ at the base of the Y-tube. Clean air was drawn through the Y-tube for at least $15 \mathrm{~min}$ before introducing the first thrips at the beginning of each bioassay. Silicone tubing connected the activated charcoal, Wheaton apparatus, Y-tube and suction pump.

Virus-free and virus-infected thrips were subjected to each of three odours: (i) a blank control, (ii) chrysanthemum buds and (iii) methyl isonicotinate (i.e. six combinations of virus status $\times$ odour in total). Four replicates, each comprising 25 thrips, of each virus/odour treatment were used (100 thrips per treatment). Three treatments were run in a day, with a complete replicate run over 2 days. The treatments and order of treatments run each day was determined with a Row-Column design, with a complete replicate in each pair of days, and a complete replicate for each of the three run orders. The design was generated by CycDesign 4.0 (CycSoftware 2009).

An individual female thrips was released into the base of the Y-tube using a small aspirator. Most thrips walked up into the Y-tube within a few seconds, at which time the silicone air suction tubing was reconnected to the base of the glass Y-tube and timing of an individual was started. When the thrips reached the far end of the respective arm their choice and the time taken was recorded. Any occasion on which a thrips failed to make a choice after 3 min was recorded as "no choice". After every five thrips, the Y-tube and Wheaton apparatus were rotated $180^{\circ}$ to avoid position effects. One replicate of a treatment was completed after 25 thrips had been placed in the Y-tube, after which the Y-tube and Wheaton apparatus were thoroughly cleaned with hexane $(99.5 \%, \mathrm{BDH})$ and allowed to dry before the next set of 25 thrips was begun.

\section{Virus status of thrips and plant material}

The virus status of thrips was determined using qRTPCR. RNA was extracted from individual thrips (approximately 10\% of the putative virusinfected and virus-free thrips) using the RNeasy Plus Mini Kit (Qiagen Inc) with RNA eluted into $20 \mu \mathrm{l}$ of RNase-free water. To design an internal control for amplification of thrips RNA, a fragment of the thrips elongation factor $1 \alpha(\mathrm{EF} 1 \alpha)$ gene was amplified and sequenced with the primers InsEF1F (TGGGTAAGGARAAGAYTCAYATTAAC) and InsEF1R (CATGCAATGTGRGCNGTGTG) that were designed from conserved regions of the insect EF1 $\alpha$ gene. A primer pair ThripsEF_1F/1R(ACGTGGTATCACCATCGACA and TTGTTCACACCAACAATCAGC) for qPCR was designed from the thrips using Primer3. The primer pair TSW.1 and TSW.R (Roberts et al. 2000) were chosen for TSWV detection. cDNA was synthesised with $5 \mu$ l RNA using the qScript ${ }^{\text {TM }}$ cDNA synthesis kit (Quanta Biosciences ${ }^{\mathrm{TM}}$ ) in a final volume of $10 \mu \mathrm{l}$. cDNA was diluted 10-fold and $2 \mu \mathrm{l}$ was used for each $20 \mu \mathrm{l}$ qPCR reaction containing $10 \mu \mathrm{l}$ iTaq SYBR Green supermix with ROX (Bio-Rad Laboratories, Inc.). Primers were at a final concentration of $500 \mathrm{nM}$. These assays was carried out in a StepOnePlus ${ }^{\mathrm{TM}}$ Real-Time PCR System (Applied Biosystems), for 40 cycles at $95^{\circ} \mathrm{C}$ for $15 \mathrm{~s}, 59^{\circ} \mathrm{C}$ for $20 \mathrm{~s}, 72^{\circ} \mathrm{C}$ for $20 \mathrm{~s}$, with an initial activation step of $95^{\circ} \mathrm{C}$ for $2 \min 30 \mathrm{~s}$.

\section{Statistical analysis}

For each experiment, the number of thrips choosing the odour-laden arm out of those that made a choice was analysed with a binomial generalised linear model (McCullagh \& Nelder 1989). The analyses included contrasts for lure type, thrips virus status and the interaction between them. These were tested with chi square test done within the analysis of deviance carried out as part of the analysis. In addition, within 
the analysis, the response for each of the six treatment combinations was compared with $50 \%$. Confidence limits of $95 \%$ for the percentage of thrips choosing the treated arm were calculated on the transformed (logit) scale, and then back-transformed.

The time taken for a thrips to make a choice was examined with the Kaplan-Meier estimate (Collett 2003) of the distribution of time taken to make a choice, and the Cox proportional hazards modelling of the distribution (Cox 1972).

All analyses were carried out with GenStat (2009, Release 12, Parts 1-3).

\section{RESULTS AND DISCUSSION}

Significantly more thrips chose the odour-laden arm of the Y-tube when it contained MI (mean $65 \%, \mathrm{P}<0.01$, Figure 1 ). The percentage was similar for both virus-free and virus-infected thrips (63\% cf. 67\%). qPCR amplification with primers for the thrips EF1a gene confirmed that consistent amounts of amplifiable RNA were obtained from all thrips (10\% of the total) examined. qPCR from these samples then showed that all putative virus-infected thrips were positive for TSWV, and all putative virus-free thrips were negative for the virus (data not shown).

Chrysanthemum buds did not increase the percentage of thrips walking up the odour-laden arm in the Y-tube above $50 \%(\mathrm{P}>0.16)$. This may have been because the amount of volatiles from a single bud was not enough to elicit a response from thrips. However, it has been shown that $10^{-6} \mu \mathrm{l}$ of MI can result in more thrips walking up the odour-laden arm than clean-air arm (Davidson et al. 2008), so thrips are capable of detecting very low quantities of semiochemicals. Alternatively, the volatiles from the plant species chosen were not attractive to western flower thrips in the Y-tube. However, chrysanthemum plants are highly attractive to western flower thrips and have been recommended as a trap crop (Buitenhuis \& Shipp 2006). Volatiles from chrysanthemum buds and flowers that had recently been infested with thrips were found to be attractive to western flower thrips when tested in a Pettersson star olfactometer (Pow et al. 1998). The present study also used chrysanthemum buds recently removed from the thrips colony, as it was thought this may have been why a previous study using a Y-tube olfactometer failed to demonstrate a response from western flower thrips females to chrysanthemum buds (Smits et al. 2000).

The Kaplan-Meier estimate of the distribution of the time taken to make a choice showed that when thrips were presented with a chrysanthemum bud they walked to either end (clean air or bud arm) of the Y-tube more rapidly than when presented

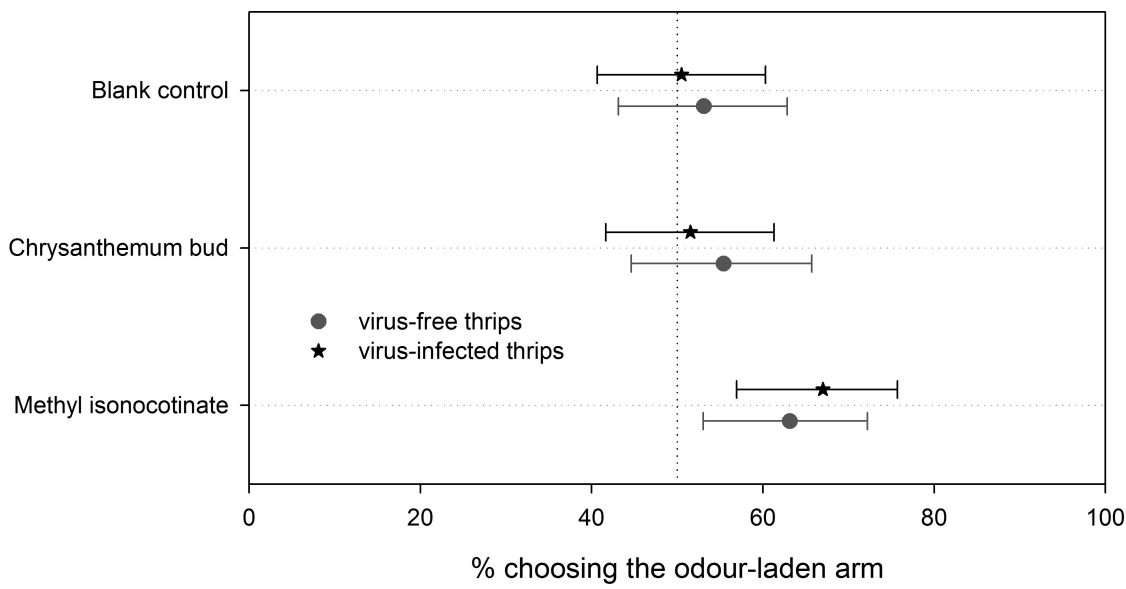

Figure 1 The mean percentage ( $\pm 95 \%$ confidence intervals) of virus-infected and virus-free thrips to walk up the odour-laden arm of a Y-tube olfactometer, for (i) blank (clean air in both arms), (ii) chrysanthemum buds and (iii) a thrips lure, methyl isonicotinate. 
with MI or no treatment (blank) (Table 1). The Cox proportional hazard modelling confirmed that the time taken to make a choice was on average shorter with a chrysanthemum bud than with either MI or the blank ( $\mathrm{P}=0.003)$. When the chrysanthemum bud was the treatment, thrips, regardless of virus status, walked to the end of an arm on average $28 \%$ more quickly than when the treatment was a blank. In contrast, with MI, thrips were only about $9 \%$ quicker to reach the end of an arm than when there was a blank treatment. The greater speed with which thrips moved to the end of an arm in the presence of chrysanthemum buds compared to MI or blank treatments suggests that the volatiles from the chrysanthemums were altering thrips behaviour. This may indicate that the presence of the chrysanthemum buds were exerting a chemokenesis stimulus (alteration in velocity in response to a chemical gradient; movement depends on intensity rather than direction of stimulus) rather than chemotaxis (movement toward or away from a chemical stimulus) (Kennedy 1977).

While methyl isonicotinate has been effective at monitoring for thrips, particularly in commercial greenhouses, and has been developed into a commercial lure (Teulon et al. 2011), the present study shows that it would not preferentially capture virus-infected over virus-free thrips. Consequently, it is unlikely to be useful for surveillance for new tospoviruses or improved monitoring for disease management.

\section{ACKNOWLEDGEMENTS}

We wish to thank Robin Gardner-Gee and David Teulon for reviewing this manuscript. This work was funded by New Zealand's Foundation for Research, Science and Technology through contract C02X0501, Better Border Biosecurity (B3) (www.b3nz.org).

\section{REFERENCES}

Collett D 2003. Modelling survival data in medical research. Texts in Statistical Science Series, v.57. Chapman Hall/ CRC Press, London. 391 p.

Cox DR 1972. Regression Models and Life-Tables. Journal of the Royal Statistical Society. Series B (Methodological) 34: 187-220.

Davidson MM, Butler RC, Teulon DA 2006. Starvation period and age affect the response of female Frankliniella occidentalis (Pergande) (Thysanoptera: Thripidae) to odor and visual cues. Journal of Insect Physiology 52: 729-736.

Davidson MM, Butler RC, Winkler S, Teulon DAJ 2007. Pyridine compounds increase trap capture of Frankliniella occidentalis (Pergande) in a covered crop. New Zealand Plant Protection 60: 56-60.

Davidson MM, Perry NB, Larsen L, Green VC, Butler RC, Teulon DAJ 2008.4-pyridyl carbonyl compounds as thrips lures: effectiveness for western flower thrips in Y-tube bioassays. Journal of Agricultural and Food Chemistry 56: 6554-6561.

Inoue T, Sakurai T 2006. Infection of Tomato spotted wilt virus (TSWV) shortens the life span of thelytokous Thrips tabaci (Thysanoptera: Thripidae). Applied Entomology and Zoology 41: 239-246.

Jones D 2005. Plant viruses transmitted by thrips. European Journal of Plant Pathology 113: 119-157.

Table 1 Summary of time (seconds) taken for thrips to walk to the end of an arm in the Y-tube (time for UQ = upper quartile (75\%), median (50\%), LQ = lower quartile (25\%)). Values are summarised over the virus-free and virus-infected thrips.

\begin{tabular}{lccccc}
\hline Lure type & UQ & Median & LQ & Mean $^{1}(\mathrm{SE})$ & \% not choosing \\
\hline Methyl isonicotinate & 55 & 26 & 16 & $45.48(2.192)$ & 5.5 \\
Chrysanthemum bud & 31 & 18 & 12 & $33.75(1.697)$ & 2.7 \\
Blank control & 57 & 22 & 14 & $42.92(1.993)$ & 3.5
\end{tabular}

${ }^{1}$ The mean time and its standard error are underestimated as several thrips had not chosen within $3 \mathrm{~min}$ (censored). 
Kennedy JS 1977. Olfactory responses to distant plants and other odour sources. In: Shorey $\mathrm{HH}$, McKelvey JJ ed. Chemical Control of Insect Behavior, Theory and Application. Wiley, New York. Pp. 67-91.

Koschier EH, De Kogel WJ, Visser JH 2000. Assessing the attractiveness of volatile plant compounds to western flower thrips Frankliniella occidentalis. Journal of Chemical Ecology 26: 2643-2655.

Lima-Camara TN, Bruno RV, Luz PM, Castro MG, Lourenco-de-Oliveira R, Sorgine MHF, Peixoto AA 2011. Dengue infection increases the locomotor activity of Aedes aegypti females. PLoS ONE 6.

Maris P, Joosten N, Goldbach RW, Peters D 2004. Tomato spoted wilt virus infection improves host suitability for its vector Frankliniella occidentalis. Phytopathology 94: 706-711.

Martin NA, Workman PJ, Butler RC 2005. Insecticide bioassays for western flower thrips (Frankliniella occidentalis) (Thysanoptera : Thripidae) and greenhouse whitefly (Trialeurodes vaporariorum) (Hemiptera : Aleyrodidae). New Zealand Journal of Crop and Horticultural Science 33: 177-184.

McCullagh P, Nelder JA 1989. Generalized Linear Models. Chapman \& Hall, London. 511+xix p.

Murai T, Ishii T 1982. Simple rearing method for flower thrips on pollen. Japanese Journal of Applied Entomology and Zoology 26: 149154.

Pow EM, Bennison JA, Birkett MA, Luszniak MJ, Manjunatha M, Pickett JA, Segers IS, Wadhams LJ, Wardlow LR, Woodcock CM 1998. Behavioural responses of western flower thrips (Frankliniella occidentalis) to host plant volatiles. Proceedings of the Sixth International Symposium on Thysanoptera, Antalya, Turkey. Pp. 121-128.
Roberts CA, Dietzgen RG, Heelan LA, Maclean DJ 2000. Real-time RT-PCR fluorescent detection of tomato spotted wilt virus. Journal of Virological Methods 88: 1-8.

Smits PH, Van Deventer P, De Kogel WJ 2000. Western flower thrips: reactions to odours and colours. Proceedings of the Section Experimental and Applied Entomology, N.E.V. 11: 175-180.

Stafford CA, Walker GP, Ullman DE 2011. Infection with a plant virus modifies vector feeding behavior. Proceedings of the National Academy of Sciences of the United States of America 108: 9350-9355.

Teulon DAJ 1992. Laboratory technique for rearing western flower thrips (Thysanoptera: Thripidae). Journal of Economic Entomology 85: 895-899.

Teulon DAJ, Davidson MM, Perry NB, Nielsen MC, van Tol RWHM, de Kogel WJ 2011. Recent developments with methyl isonicotinate, a semiochemical used in thrips pest management. New Zealand Plant Protection 64: 287.

Teulon DAJ, Davidson MM, Hedderley DI, James DE, Fletcher CD, Larsen L, Green VC, Perry NB 2007. 4-Pyridyl carbonyl and related compounds as thrips lures: effectiveness for onion thrips and New Zealand flower thrips in field experiments. Journal of Agricultural and Food Chemistry 55: 6198-6205.

Wetering Fvd, Goldbach R, Peters D 1996. Tomato spotted wilt tospovirus ingestion by first instar larvae of Frankliniella occidentalis is a prerequisite for transmission. Phytopathology 86: 900-905.

Whitfield A, Ullman DE, German T 2005. Tospovirus-thrips interactions. Annual Review of Phytopathology 43: 459-489. 